\title{
DIABETIC RETINITIS IN A PATIENT AGED TWENTY-TWO
}

\author{
BY \\ P. H. Adams \\ OXFORD
}

DIABETIC retinitis is commonly regarded as a late condition found in elderly diabetics and considered to be secondary to the vascular changes which occur, rather than to the diabetes as such. The following case, therefore, seems to be of sufficient interest and importance to justify publication.

C. H., aged 22 years, came to the Oxford Eye Hospital, on October 16, 1931, complaining of pain in the right eye for the past week. On examination, the right eye was injected and the pupil was filled by a greyish exudate which also obscured all details of the iris. The left eye was quite quiet, pupil circular and active, and iris normal.

V., R. Hand movements. L. 6/9.

He was admitted to hospital, and the urine was found to contain a large quantity of sugar. He was treated for the iritis and in 5 days the exudation had absorbed.

October 24. On examination of the right fundus by my house surgeon, Miss Belt, she found the superior temporal vein somewhat engorged, with some yellowish areas of retinitis at the macula.

Urine, sp. gr. 1015. Sugar, $2 \cdot 2$ per cent.

He was examined by Dr. Stobie, physician to out-patients at the Oxford Eye Hospital, who found the blood pressure 100/75. Knee jerks, right side, just present. Left side quite definite. Wassermann reaction, negative.

October 27, 1931. I made a further examination and found definite yellowish areas of retinitis just above the macula, below the superior temporal artery, and also some fine flecks just below the macula. There was a particularly well marked shot-silk reflex round the macular region, especially on the outer side and about three discs breadth to the inner side of the disc there was a small mossy haemorrhage.

Left eye. There was a similar well marked shot-silk reflex round the macula; about 1 disc's breadth up and in from the disc was a small mossy haemorrhage and there were several small punctate haemorrhages scattered about the fundus. There were no obvious signs of disease in the retinal blood vessels.

Dr. W. T. Collier, physician to the Radcliffe Infirmary, kindly examined the patient for me and reported as follows:- "I can find nothing abnormal in this boy, apart from the diabetic condition. Examination of heart, lungs and abdomen, negative. The urine contained a very fair amount of sugar, a very faint trace of albumen 
and no acetone or diacetic acid. The blood sugar at 2.30 p.m. was 0.3 per cent."

On enquiring into the past history, I was informed that the diabetes was discovered first about two years ago when he had had some injections of insulin. On the suggestion being made of this treatment being resumed, the man promptly bolted and we have seen no more of him.

We have here then a definite case of diabetic retinitis in one eye and typical haemorrhages in the other eye in a man of 22 years of age without obvious signs of diseased blood vessels and with a blood pressure of only $100 / 75$.

\section{COMMUNIQUE}

\section{International Association for the Prevention of Blindness}

The General Assembly of the International Association for the Prevention of Blindness was held in Paris, 2, Avenue Vélasquez, on Saturday, November 14, 1931, at 2 p.m., under the Chairmanship of Prof. de Lapersonne. The numerous personalities attending this meeting included: Mlle. de Teincey, representing H.R.H. the Duchess de Vendôme; M. Lévesque, representing the Minister of Health; M. Pigot, representing the Direction of Public Health; Military Intendant Bouscasse, representing General Pau, Chairman of the French Red Cross; Countess de Galard and Madame Barbier-Hugo, Presidents of two branches of the French Red Cross; Prof. Terrien and Dr. Morax (France); Dr. Pantaleoni, representing the League of Nations; Dr. Park Lewis, Vice-President of the International Association and of the National Society for the Prevention of Blindness, representing the United States; Prof. van Duyse (Belgium); Dr. MacCallan; Dr. and Mrs. Cridland (Great Britain); Prof. van der Hoeve (Netherlands); Prof. de Grosz (Hungary); Prof. Angelucci and Prof. Maggiore (Italy); Dr. Marquez (Spain); Dr. Zachert (Poland); Dr. Lossouarn, Chairman of the Chinese League for the Prevention of Blindness; Dr. Patry (Switzerland); etc.

PROF. DE LAPERSONNE outlined the work accomplished by the Association during the past year, laying particular emphasis on the formation of National Committees in the Argentine, Belgium, Brazil, France, Germany, Hungary, Italy, Mexico, Poland, Portugal and Spain. He pointed out that the composition of these Committees should be as representative as possible, the object of the Association being to reach all classes of the community. He reminded his audience of the great work done in America and Great 